\title{
The Shape of Eurozone's Uncertainty: Its Impact and Predictive Value on GDP
}

\author{
Ralf Fendel $^{1}$, Nicola $\mathrm{Mai}^{2} \&$ Oliver Mohr ${ }^{1,2}$ \\ ${ }^{1}$ WHU - Otto Beisheim School of Management, \\ ${ }^{2} \mathrm{PIMCO}$ \\ Correspondence: Ralf Fendel, WHU - Otto Beisheim School of Management, Burgplatz 2, 56179 Vallendar, Germany. \\ The views expressed in this paper are those of the authors and do not constitute official PIMCO views.
}

Received: July 17, 2020

Accepted: September 10, 2020

Available online: September 30, 2020

doi:10.11114/aef.v7i6.5033

URL: https://doi.org/10.11114/aef.v7i6.5033

\begin{abstract}
This paper examines the role of uncertainty in the context of the business cycle in the euro area. To gain a more granular perspective on uncertainty, the paper decomposes uncertainty along two dimensions: First, we construct the four different moments of uncertainty, including the point estimate, the standard deviation, the skewness and the kurtosis. The second dimension of uncertainty spans along three distinct groups of economic agents, including consumers, corporates and financial markets. Based on this taxonomy, we construct uncertainty indices and assess the impact on real GDP via impulse response functions and further investigate their informational value in rolling out-of-sample GDP forecasts. The analysis lends evidence to the hypothesis that higher uncertainty expressed through the point estimate, a larger standard deviation among confidence estimates, positive skewness and a higher kurtosis are all negatively correlated with the business cycle. The impulse response functions reveal that in particular the first and the second moment of uncertainty cause a permanent effect on GDP with an initial decline and a subsequent overshoot. We find uncertainty in the corporate sector to be the main driver behind this observation, followed by financial markets' uncertainty whose initial effect on GDP is comparable but receding much faster. While the first two moments of uncertainty improve GDP forecasts significantly, both the skewness and the kurtosis do not augment the forecast quality any further.
\end{abstract}

JEL Classification: D8, E23, E27, E32, E37.

Keywords: uncertainty, Euro area, business cycle, GDP forecast, VAR

\section{Introduction}

The purpose of this paper is to shed light on the role of uncertainty in the context of business cycle dynamics in the euro area. There is consensus in existing literature that uncertainty among economic agents has a measurable effect on real economic variables. However, researchers seem to be divided on the question of how to define uncertainty, which ultimately determines its measurement and quantification. Concepts of uncertainty range from observable measures such as implied volatilities on financial markets and sentiment indices on the one end of the spectrum to Knightian uncertainty (Knight, 1921) on the other end, aspiring to observe the unobservable. To bridge the gap between these different ideas about uncertainty, this paper first decomposes uncertainty into different layers along the four moments of the distribution: We define the first moment as the general confidence level that economic agents state explicitly in surveys or implicitly via financial market risk premia. The second, third and fourth moment of uncertainty focuses on the shape of the distribution of confidence estimates and implied volatilities in terms of the standard deviation, the skewness and the kurtosis. To capture uncertainty holistically for the economy, we consider three types of economic groups: the consumer, corporates and financial markets. Subsequently, we construct aggregate measures of uncertainty across these agents for the four moments and qualitatively assess their behavior vis-à-vis the business cycle. A second area of interest is the quantitative impact of uncertainty on GDP considering a parsimonious specification of the business cycle in a VAR. The third perspective focuses on the informative value that the different moments of uncertainty provide to GDP forecasts. We subsequently validate results of the third perspective by examining how much of the variation in the second moment of uncertainty is actually driven by the first moment. 
This paper has the following structure. The second section provides a literature review covering the three economic groups and the four moments of uncertainty. The third section presents the model set-up and the underlying data of the analysis. The fourth section analyzes the shape of uncertainty vis-à-vis the business cycle from a qualitative perspective and continues with a quantitative analysis on the impact of uncertainty on real GDP via impulse response functions. Section five assesses the informational value of the four moments in the context of their forecasting performance on real GDP. To account for potential endogeneity, this section concludes with an analysis that sheds light on the relationship between the first and the second moment of the distribution. Section six concludes with a brief summary.

\section{Literature Review}

The relevant breeding places of uncertainty can be broadly classified into three groups of agents whose activities ultimately affect the real economy. At the very core of these inherently unobservable dynamics are consumers and corporations who determine the demand and the supply side of the economy. Both economic agents can develop uncertainty for a multiple of endogenous reasons related to the current stance of the business cycle. Representing a third group, financial market participants and their lack of confidence can create exogenous shocks on consumers and corporations alike through changes in financial conditions. As the actual interplay between these three economic groups is very nuanced without clear-cut causality, this sections sheds light on each representative agent separately. Subsequently, we review findings on the different moments of uncertainty and their informational value regarding the business cycle.

\subsection{Consumers}

Households form expectations about several interdependent variables that determine in aggregation their course of action. These expectations cover the macroeconomic perspective (e.g. general economic situation, price trends) and the individual outlook (e.g. personal financial position, employment status, income situation and major purchases). Increasing uncertainty in these areas affects two transmission channels: The timing and the composition of consumption spending. According to most lifecycle models of consumption, a higher level of uncertainty has long been associated with higher levels of precautionary savings to self-insure through a delay of consumption (Deaton (1991), Caballero (1991)), even though some studies have casted doubts on this causality (Dynan 1993). Christelis et al. (2016) analyze the motives behind changes in savings based on a sample of Dutch households. While previous empirical research has predominantly used ex-post consumption as an input factor into the Euler equation, the authors sidestep potential questions of endogeneity by referring to consumption expectations and can confirm strong precautionary savings in the presence of uncertainty.

The second transmission mechanism of consumer uncertainty is a change in the composition of purchases. However, literature is less conclusive on the proposed causality. Proponents of this channel argue that consumers will delay spending on durables caused by temporary income uncertainty. Romer (1990) notes that during the period of the Great Depression in 1929, consumption of durables has declined while spending on non-durables has increased. ${ }^{1}$ Contrary to her findings, research on the post-war era finds a negative relationship between income uncertainty and spending on non-durables based on survey data (Hahm and Steigerwald (1999), Madsen and McAleer (2000)).

\subsection{Corporations}

The effects of uncertainty surrounding the business outlook of corporations are weighing ultimately on the real economy from two different angles: Investments in capital goods and hiring decisions, the later feeding into consumer uncertainty. First, investment spending requires decision makers to assess the confidence level of their forecasts. According to the 'wait-and-see' effect, companies could opt to defer an investment decision until an updated set of information increases their confidence. Bernanke (1983) provides theoretical foundation that it is reasonable for companies to defer irreversible investments in the light of uncertainty, if the value of the information gained by waiting exceeds the costs of postponing a decision. In a model of risk-neutral agents in an energy-importing economy, Bernanke shows that uncertainty increases the value of incoming information which increases, in turn, the benefits of waiting. Hence, uncertainty depresses investments in the short-run and contributes to business cycle fluctuations. Pindyck (1991) argues that the 'wait-and-see' effect needs consideration when dealing with the future value of objects, which are inherently difficult to value. A wilderness area, for example, requires an adequate stochastic modeling of its value before starting its economic exploitation. In fact, the option value of waiting should be added as a foregone opportunity expressed as direct costs to the destruction of the wilderness area. Stokey (2016) develops a model of investment decisions where a change in tax policy induces corporations into a 'wait-and-see mode'. After gaining full insights into the newly introduced fiscal legislation, companies undertake the postponed, irreversible investment projects which lead to a temporary investment boom. While Bachmann et al. (2013) confirm in an SVAR that uncertainty shocks can create

\footnotetext{
${ }^{1}$ Romer (1990) uses stock market volatility as a proxy for uncertainty.
} 
protracted negative impulses on economic activity, they emphasize the possibility of a reverse causality. In fact, the authors discuss the idea that uncertainty is not an autonomous source of economic fluctuations, but rather a result of a negative first moment shock in the economy. Their analysis is based on business surveys from the US and Germany covering manufacturing firms ${ }^{2}$ by modeling the ex-ante dispersion and the realized forecast errors.

Regarding the second transmission channel, hiring decisions under uncertainty are likely to impact both the demand side, through the purchasing power of consumers, and the supply side of an economy, through the size of production capacity. As turning points of economic cycles are inherently difficult to predict, firms could seek for a fuller set of information before changing the level of their workforce in the presence of inhibiting labor market regulation. Arellano et al. (2011) establish a general equilibrium model that incorporates employment decisions of heterogenous firms under imperfect financial markets. Firms are facing the trade-off between increasing returns as a function of labour and higher risk of default in case of demand shocks. According to the authors, a higher variance of expected aggregate demand leads to a fall in employment. Along similar lines, Ernst and Viegelahn (2014) develop an indicator reflecting hiring uncertainty among employers. Based on a modified investment model of McDonald and Siegel (1986), the authors determine two labour productivity thresholds at which firms start to hire or lay off workers facing a return and cost trade-off. The authors infer the level of hiring uncertainty based on a function of the actual hiring decisions by firms incorporating the observed labour productivity level within the economy. Results lend support to the hypothesis that labour markets play a crucial transmission mechanism of uncertainty. Despite the general notion in literature to connote uncertainty with a dampening effect, there is theoretical support for the opposite idea that uncertainty can actually increase hiring and investment through growth options and the Oi-Hartman-Abel effect ${ }^{3}$. While the idea of growth options refers to the upside potential of entering new product or regional markets providing a positive skew of potential returns, the Oi-Hartman-Abel effect relies on the assumption that profits are convex in costs and demand. Assuming that firms are able to increase and decrease production on the basis of a new information set, demand or cost uncertainty actually increase potential profits.

\subsection{Financial Markets}

Uncertainty among financial market participants can affect both the supply and the demand side of the economy through changes in financial conditions. However, the causality between uncertainty and a change in financial conditions often remains ambiguous: On the one hand, uncertainty can originally emerge within financial markets creating an exogenous shock that leads to tightening of financial conditions and a subsequent slump in investment and consumption. On the other hand, uncertainty could act as an amplification mechanism of the endogenous business cycle when financial markets react to an updated set of information about changing economic conditions. The related adjustment of risk premia could open a feedback channel in response to already existing economic dynamics. Gilchrist et al. (2014) establish a general equilibrium model and use micro and macro-level data to analyze the effect of innovations in credit spreads on investments. According to their model incorporating financial frictions, an increase in uncertainty leads to a sharp and persistent widening of credit spreads that cause corporations to cut investment spending and decrease their leverage. The authors highlight the significance of financial risk premia as a primary source for a decline in investments and cast doubts on the relative importance of the 'wait-and-see' effect. Given their high frequency and availability, volatility indices of equity markets have been a preferred measure of uncertainty (Bekaert et al. (2013)) and served for benchmarking purposes of alternative uncertainty measures (Leduc and Liu (2016)). Caggiano et al. (2017) use the $\mathrm{VXO}^{4}$ as the dummy variable within a non-linear VAR model to analyze whether uncertainty is state-contingent based on U.S. data. Their results point to a larger effect of uncertainty during recessions with a sharp drop and subsequent recovery of unemployment and output. In expansionary phases, real economic variables react to a much lesser degree to an uncertainty shock with only limited evidence for overshooting.

\subsection{Shape of Uncertainty}

As researchers tend to define uncertainty in their specific own ways without converging to a broadly shared concept, we first categorize the various approaches along the different moments of the distribution: the point estimate, the standard deviation, the skewness and the kurtosis. The most direct way of gaining an estimate about the level of uncertainty within the economy is to address uncertainty via surveys which represents the most observable component of uncertainty. Emerging new technologies for the screening of large datasets have provided researchers with new perspectives on point estimates of uncertainty in addition to more traditional surveys. Baker et al. (2016) published a

\footnotetext{
2 The surveys are the German IFO Business Climate Survey and the Philadelphia Fed's Business Outlook Survey.

${ }^{3}$ The idea can be attributed to work by Oi (1961), Hartman (1972) and Abel (1983).

${ }^{4}$ The authors acknowledge that the VXO, a measure of volatility of the S\&P 100, capture a mixture between risk and uncertainty.
} 
policy uncertainty index based on the screening of 12,000 newspaper articles for a specified word combination. This concept relies on the idea that journalists represent a qualitative filter that adequately reflects the level of uncertainty of economic decision makers. The obvious limitations to this approach is the ex-post selection of keywords and the reliance on the media to capture uncertainty in their writings.

A second stream of literature considers a measure related to the second moment of the distribution. A larger standard deviation is commonly interpreted as increasing uncertainty. Haddow et al. (2013) include amongst other variables implied volatility levels and dispersion among forecasters (GDP, company earnings) as input factors into their uncertainty index for the UK. Adrian and Brunnermeier (2016) propose a modified version of a VaR to detect systemic stress. The authors establish a VaR conditional on a financial institution being under distress relative to its median state and identify leverage, size, and asset price booms as predictors for periods of systemic risk. Representing another perspective through the lens of the standard deviation, Rossi and Sekhposyan (2015) consider forecast error distributions to infer the degree of uncertainty.

Literature that explicitly considers the third and the fourth moment, the skewness and the kurtosis, is most prominent in financial market literature given sufficient availability of price data, whereas fewer studies look at economic variables as well. Ferreira (2018) measures the skewness of cross-sectional stock market returns for financial firms in the US and finds superior predictive power as compared to other aggregate uncertainty measures of aggregate uncertainty (Jurado et al. (2015)) or corporate bond spreads (e.g. Gilchrist and Zakrajsek (2012)). Based on data from 1926 to 2015, Ferreira (2018) highlights that financial firms diversify away non-systemic risks through asset portfolio choices and their returns provide a useful signal that bridges the gap between financial market valuation and real economic dynamics. Guvenen et al. (2015) analyze individual labor earnings for the US and find strong deviation from lognormality in the presence of earnings shocks. In particular, results show significant negative skewness and high kurtosis in times of economic distress. Moreover, asymmetries between income cohorts and stages of the life-cycle arise as negative earnings shocks show higher negative skewness for older people given lower upside surprises and higher disaster risk.

\section{Model Set-Up and Data}

The conceptual framework of this paper is to deconstruct what is commonly perceived as uncertainty along two dimensions: different moments of uncertainty and different economic agents.

\subsection{Moments of Uncertainty}

One of the challenges that researchers are facing in their attempt to capture uncertainty is to clearly differentiate between the different moments. In particular, the overlap between sentiment, the general confidence level and less observable components of uncertainty is a source of ambiguity. Hence, we employ four different moments: The first moment is the point estimate related to the general confidence level which is directly observable in surveys and market risk premia; the second moment represents the standard deviation around this point estimate; the third moment measures the skewness; and the fourth moment captures the kurtosis. To quantify these measures, the analysis identifies confidence surveys for the consumer and the corporate sector which include data for various subsectors. ${ }^{5}$ This procedure allows for calculating the latter moments of the distribution based on the same dataset to achieve consistency with the first moment.

The first moment is defined as the average confidence level of the different subsectors. To facilitate the interpretation, we standardize and invert the time series. Hence, an increase of the index points to higher uncertainty.

The second moment, the standard deviation, is included to describe the overall dispersion of expectations according to the standard formula for the total population:

$$
S D=\sqrt{\frac{1}{N} \sum_{i=1}^{N}\left\lceil A_{i}-\mu\right\rceil^{2}}
$$

$\mathrm{N}$ describes the number of observations; A denotes the respective value of the subsector; and $\mu$ describes the mean which coincides with the first moment. ${ }^{6}$ We assume that a wider distribution of confidence levels is indicative of a more uncertain prognosis. As economic agents do not form expectations in isolation, a higher dispersion of forecasts

\footnotetext{
${ }^{5}$ The procedure for financial markets deviates slightly given different type of data.

${ }^{6}$ This nomenclature applies for the other formulas as well.
} 
within a group of economic agents will likely lower their confidence in their own point estimates.

The third moment of the distribution, the skewness, describes the symmetry of the distribution:

$$
S K=\frac{\frac{1}{n} \sum_{i=1}^{n}\left(x_{i}-\mu\right)^{3}}{\left(\sqrt{\frac{1}{n} \sum_{i=1}^{n}\left(x_{i}-\mu\right)^{2}}\right)^{3}}
$$

If the shape of the distribution displays a longer tail to the right, skewness is considered to be positive. If a distribution is described by a longer tail to the left, skewness is negative. We examine whether outliers, that gather systematically on one of the ends of the distribution, carry informational value vis-à-vis the business cycle. Our hypothesis is that during periods of confidence, corporates and consumers gather around the average point estimate with negative outliers to the left, creating a negative skew. Following Keynes' animal spirits, we interpret behavior of economic agents as pro-cyclical. Hence, a benign economic outlook will cause survey respondents to herd around higher levels in confidence indices with less room for positive outliers and more room for pessimists who, speaking in statistical terms, pull the mean below the median. In times of higher uncertainty, however, point estimates will shift to the left and eliminate the left skew with outliers emerging on the right. Bernhardt et al. (2006) develop a robust frequency test for herding behavior based on quarterly individual forecasts of professional analysts on earnings-per-share (EPS) announcements for the period between 1989 and 2001. The authors find that analysts systematically overshoot actual EPS in nearly $60 \%$ of the cases which lends support to our hypothesis that good economic times lead to a majority of forecasts gathering around overly optimistic levels creating room for outliers to the downside and corresponding negative skewness.

The fourth moment, kurtosis, is a measure to characterize the flatness of the distribution.

$$
K=\frac{\frac{1}{n} \sum_{i=1}^{n}\left(x_{i}-\mu\right)^{4}}{\left(\frac{1}{n} \sum_{i=1}^{n}\left(x_{i}-\mu\right)^{2}\right)^{2}}
$$

The standard normal distribution is described by a value of 3 . If a distribution is rather equally distributed around the point estimate, platykurtic, it displays thinner tails (values below 3). A peaked distribution is called leptokurtic, with higher consensus around the central estimate and fatter tails (values above 3). We assume that a leptokurtic distribution represents situations of high consensus among the majority of economic agents with more extreme outliers on both ends. Thus, we suspect binary events with diverging views on the extremes and herding behavior in the center to produce a leptokurtic shape. As kurtosis represents a latter moment, we are cautious to not interpret it on an isolated basis but rather in an integrated perspective together with the point estimate, the standard deviation and the skewness.

\subsection{Economic Agents}

We determine the point estimate, the standard deviation, the skewness and the kurtosis for the following economic groups: consumers, corporates and financial market participants. The dataset for the euro area spans from the introduction of the euro in January 1999 until June 2018 and applies a quarterly perspective.

Data on the consumer group is based on the European Commission Business and Consumer Survey ${ }^{7}$ that considers currently more than 41,000 consumers across the European Union ${ }^{8}$. For this study, we identify six strictly forward looking survey questions ${ }^{9}$ that assess expectations among consumers over the next $12 \mathrm{mths}$ on following perspectives: their financial situation, the general economic situation, unemployment expectations, future savings, major purchases and price trends. Each of these variables is provided for four different income cohorts which provides a total of 24 time series which we standardize (see Table 1a). We then determine the four moments of uncertainty across the different

\footnotetext{
${ }^{7} \mathrm{We}$ assume that uncertainty in the broader European Union and the euro area is largely congruent as the largest contributors to GDP (except for the UK) are members of both communities.

${ }^{8}$ To achieve comparability, national statistics institutes use a harmonized questionnaire and a common timetable.

${ }^{9}$ We exclude variables that ask about the current state and past observations.
} 
time series for each point in time. The afore-mentioned variables are almost entirely positively correlated ${ }^{10}$ after changing the sign of the outlook on unemployment. Hence, dispersion does not arise due to a change in direction of the point estimate. As the main hypothesis, we assume that greater variation within the dataset at a particular point in time across different questions and income cohorts is a sign for increasing uncertainty among consumers. While this assumption may be vulnerable to fundamental factors that drive a wedge between different types of expectations, we claim that the representative consumer cannot rationally adjust his outlook consistently across all items causing differences on the relative stance of each time series.

Table 1a. Data on the Consumer

\begin{tabular}{|c|c|}
\hline Data series & Data period \\
\hline EA19: Fin Situation Next 12 Mo: Income 1st Quartile, Balance (SA, \%) & Q1/1999-Q2/2018 \\
\hline EA19: Gen Eco Situation Next 12 Mo: Income 1st Quartile, Balance (SA, \%) & Q1/1999-Q2/2018 \\
\hline EA19: Unemp Exp Next 12 Mo: Income 1st Quartile, Balance (SA, \%) & $\mathrm{Q} 1 / 1999-\mathrm{Q} 2 / 2018$ \\
\hline EA19: Savings Next 12 Mo: Income 1st Quartile, Balance (SA, \%) & Q1/1999-Q2/2018 \\
\hline EA19: Major Purchases Next 12 Mo: Income 1st Quartile, Balance (SA, \%) & $\mathrm{Q} 1 / 1999-\mathrm{Q} 2 / 2018$ \\
\hline EA19: Price Trends Next 12 Mo: Income 1st Quartile, Balance (SA, \%) & $\mathrm{Q} 1 / 1999-\mathrm{Q} 2 / 2018$ \\
\hline EA19: Fin Situation Next 12 Mo: Income 2nd Quartile, Balance (SA, \%) & Q1/1999-Q2/2018 \\
\hline EA19: Gen Eco Situation Next 12 Mo: Income 2nd Quartile, Balance (SA, \%) & Q1/1999-Q2/2018 \\
\hline EA19: Unemp Exp Next 12 Mo: Income 2nd Quartile, Balance (SA, \%) & Q1/1999-Q2/2018 \\
\hline EA19: Savings Next 12 Mo: Income 2nd Quartile, Balance (SA, \%) & $\mathrm{Q} 1 / 1999-\mathrm{Q} 2 / 2018$ \\
\hline EA19: Major Purchases Next 12 Mo: Income 2nd Quartile, Balance (SA, \%) & Q1/1999-Q2/2018 \\
\hline EA19: Price Trends Next 12 Mo: Income 2nd Quartile, Balance (SA, \%) & Q1/1999-Q2/2018 \\
\hline EA19: Fin Situation Next 12 Mo: Income 2nd Quartile, Balance (SA, \%) & $\mathrm{Q} 1 / 1999-\mathrm{Q} 2 / 2018$ \\
\hline EA19: Gen Eco Situation Next 12 Mo: Income 2nd Quartile, Balance (SA, \%) & $\mathrm{Q} 1 / 1999-\mathrm{Q} 2 / 2018$ \\
\hline EA19: Unemp Exp Next 12 Mo: Income 2nd Quartile, Balance (SA, \%) & $\mathrm{Q} 1 / 1999-\mathrm{Q} 2 / 2018$ \\
\hline EA19: Savings Next 12 Mo: Income 2nd Quartile, Balance (SA, \%) & $\mathrm{Q} 1 / 1999-\mathrm{Q} 2 / 2018$ \\
\hline EA19: Major Purchases Next 12 Mo: Income 2nd Quartile, Balance (SA, \%) & $\mathrm{Q} 1 / 1999-\mathrm{Q} 2 / 2018$ \\
\hline EA19: Price Trends Next 12 Mo: Income 2nd Quartile, Balance (SA, \%) & $\mathrm{Q} 1 / 1999-\mathrm{Q} 2 / 2018$ \\
\hline EA19: Fin Situation Next 12 Mo: Income 4th Quartile, Balance (SA, \%) & $\mathrm{Q} 1 / 1999-\mathrm{Q} 2 / 2018$ \\
\hline EA19: Gen Eco Situation Next 12 Mo: Income 4th Quartile, Balance (SA, \%) & $\mathrm{Q} 1 / 1999-\mathrm{Q} 2 / 2018$ \\
\hline EA19: Unemp Exp Next 12 Mo: Income 4th Quartile, Balance (SA, \%) & $\mathrm{Q} 1 / 1999-\mathrm{Q} 2 / 2018$ \\
\hline EA19: Savings Next 12 Mo: Income 4th Quartile, Balance (SA, \%) & Q1/1999-Q2/2018 \\
\hline EA19: Major Purchases Next 12 Mo: Income 4th Quartile, Balance (SA, \%) & $\mathrm{Q} 1 / 1999-\mathrm{Q} 2 / 2018$ \\
\hline EA19: Price Trends Next 12 Mo: Income 4th Quartile, Balance (SA, \%) & $\mathrm{Q} 1 / 1999-\mathrm{Q} 2 / 2018$ \\
\hline $\begin{array}{l}\text { 1st Moment of Uncertainty: Average } \\
\text { 2nd Moment of Uncertainty: Standard Deviation } \\
\text { 3rd Moment of Uncertainty: Skew } \\
\text { 4th Moment of Uncertainty: Kurtosis }\end{array}$ & \\
\hline
\end{tabular}

Source: European Commission Business and Consumer Survey

On the corporate sector, we again consider survey data by the European Commission Business and Consumer Survey that is surveying 130,000 firms to infer the confidence levels of various industries ${ }^{11}$. For our analysis, we identify subsectors whose time series reaches back to the start of the EMU and exclude overlapping categories. The calculation of the different moments is then conducted across 27 standardized time series at a particular point in time (see Table 1b). Given integrated supply chains, companies do not conduct their forecasting processes in isolation. Hence, we interpret a greater divergence between the confidence of sectors as a signal of uncertainty that could impact real economic decisions.

$1095.1 \%$ of covariances of the 24 time series are positive.

11 The survey differs between countries and covers expectations on production, exports, hiring activity and the broader business sentiment. 
Table 1b. Data on the Corporate Sector

\begin{tabular}{|c|c|}
\hline Data Series & Data period \\
\hline EA19: Consumer Goods: Confidence Indicator, Balance (SA, \%) & Q1/1999-Q2/2018 \\
\hline EA19: Investment Goods: Confidence Indicator, Balance (SA, \%) & $\mathrm{Q} 1 / 1999-\mathrm{Q} 2 / 2018$ \\
\hline EA19: Intermed Goods, ex Mining/Quarrying: Confidence Indicator, Balance (SA, \%) & $\mathrm{Q} 1 / 1999-\mathrm{Q} 2 / 2018$ \\
\hline EA19: Food And Bev: Confidence Indicator, Balance (SA, \%) & $\mathrm{Q} 1 / 1999-\mathrm{Q} 2 / 2018$ \\
\hline EA19: Textiles: Confidence Indicator (SA, \% Bal) & $\mathrm{Q} 1 / 1999-\mathrm{Q} 2 / 2018$ \\
\hline EA19: Wearing Apparel: Confidence Indicator (SA, \% Bal) & $\mathrm{Q} 1 / 1999-\mathrm{Q} 2 / 2018$ \\
\hline EA19: Leather \& Related Products: Confidence Indicator (SA, \% Bal) & $\mathrm{Q} 1 / 1999-\mathrm{Q} 2 / 2018$ \\
\hline EA19: Wood Products: Confidence Indicator (SA, \% Bal) & $\mathrm{Q} 1 / 1999-\mathrm{Q} 2 / 2018$ \\
\hline EA19: Paper Products: Confidence Indicator (SA, \% Bal) & $\mathrm{Q} 1 / 1999-\mathrm{Q} 2 / 2018$ \\
\hline EA19: Reproduction of Media: Confidence Indicator (SA, \% Bal) & $\mathrm{Q} 1 / 1999-\mathrm{Q} 2 / 2018$ \\
\hline EA19: Chemicals: Confidence Indicator (SA, \% Bal) & $\mathrm{Q} 1 / 1999-\mathrm{Q} 2 / 2018$ \\
\hline EA19: Rubber \& Plastic Products: Confidence Indicator (SA, \% Bal) & $\mathrm{Q} 1 / 1999-\mathrm{Q} 2 / 2018$ \\
\hline EA19: Non-Metallic Mineral Products: Confidence Indicator (SA, \% Bal) & $\mathrm{Q} 1 / 1999-\mathrm{Q} 2 / 2018$ \\
\hline EA19: Basic Metals: Confidence Indicator (SA, \% Bal) & $\mathrm{Q} 1 / 1999-\mathrm{Q} 2 / 2018$ \\
\hline EA19: Fabricated Metal Products: Confidence Indicator (SA, \% Bal) & Q1/1999-Q2/2018 \\
\hline EA19: Electronic \& Optical Products: Confidence Indicator (SA, \% Bal) & $\mathrm{Q} 1 / 1999-\mathrm{Q} 2 / 2018$ \\
\hline EA19: Electrical Equipment: Confidence Indicator (SA, \% Bal) & $\mathrm{Q} 1 / 1999-\mathrm{Q} 2 / 2018$ \\
\hline EA19: Machinery \& Equipment: Confidence Indicator (SA, \% Bal) & $\mathrm{Q} 1 / 1999-\mathrm{Q} 2 / 2018$ \\
\hline EA19: Motor Vehicles \& Trailers: Confidence Indicator (SA, \% Bal) & $\mathrm{Q} 1 / 1999-\mathrm{Q} 2 / 2018$ \\
\hline EA19: Furniture: Confidence Indicator (SA, \% Bal) & Q1/1999-Q2/2018 \\
\hline EA19: Other Manufacturing: Confidence Indicator (SA, \% Bal) & $\mathrm{Q} 1 / 1999-\mathrm{Q} 2 / 2018$ \\
\hline EA19: Trade \& Repair of Motor Vehicles: Confidence Indicator (SA, \% Bal) & Q1/1999-Q2/2018 \\
\hline EA19: Sale of Motor Vehicles: Confidence Indicator (SA, \% Bal) & $\mathrm{Q} 1 / 1999-\mathrm{Q} 2 / 2018$ \\
\hline EA19: Motor Vehicles \& Accessories: Confidence Indicator (SA, \% Bal) & $\mathrm{Q} 1 / 1999-\mathrm{Q} 2 / 2018$ \\
\hline EA19: Retail Trade, Excl Motor Vehicles: Confidence Indicator (SA, \% Bal) & $\mathrm{Q} 1 / 1999-\mathrm{Q} 2 / 2018$ \\
\hline EA19: Retail Sale of Food/Beverages/Tobacco: Confidence Indicator (SA, \% Bal) & Q1/1999-Q2/2018 \\
\hline EA19: Retail Sale of Other Goods: Confidence Indicator (SA, \% Bal) & $\mathrm{Q} 1 / 1999-\mathrm{Q} 2 / 2018$ \\
\hline $\begin{array}{c}\text { 1st Moment of Uncertainty: Average } \\
\text { 2nd Moment of Uncertainty: Standard Deviation } \\
\text { 3rd Moment of Uncertainty: Skew } \\
\text { 4th Moment of Uncertainty: Kurtosis }\end{array}$ & \\
\hline
\end{tabular}

Source: European Commission Business and Consumer Survey

Regarding financial market data, the paper deviates from the previous procedure given the different nature of available data (see Table 1c). For the first moment, we refer deliberately to a parsimonious representation through the option-adjusted spread (OAS) on EUR denominated corporate bonds. According to existing literature, the OAS has the ability to capture investors' confidence in the current business cycle. Gilchrist et al. (2014) emphasize that changes in credits spread are the primary driver of the business cycle. The inclusion of the credit spread as the first moment should provide insights into the discussion of how much of uncertainty can be attributed to the general confidence on credit markets and what is caused by the less observable parts of uncertainty expressed as the latter moments. For the standard deviation, skewness and kurtosis, the study uses option implied volatilities of three segments: different asset classes (equity, rates and gold as a store of value), FX market (currency pairs versus the EUR to reflect flight-to-safety dynamics and fundamental trade flows) and commodities (energy, industrial and agriculture). To ensure data consistency among the various dimensions, we refer wherever possible to the $3 \mathrm{~m}$ option implied volatility and convert daily values into quarterly observations via their average over the quarter. For the calculation of the second moment, we take the weighted average of the implied option values across the time series as soon as they become available given different starting dates. The third and fourth moment looks at the skewness ${ }^{12}$ and kurtosis of the standardized implied volatilities across the different asset classes.

${ }^{12}$ We assume that positive skewness indicates increasing concerns about an upcoming spike in volatility. 
Table 1c. Data on Financial Markets

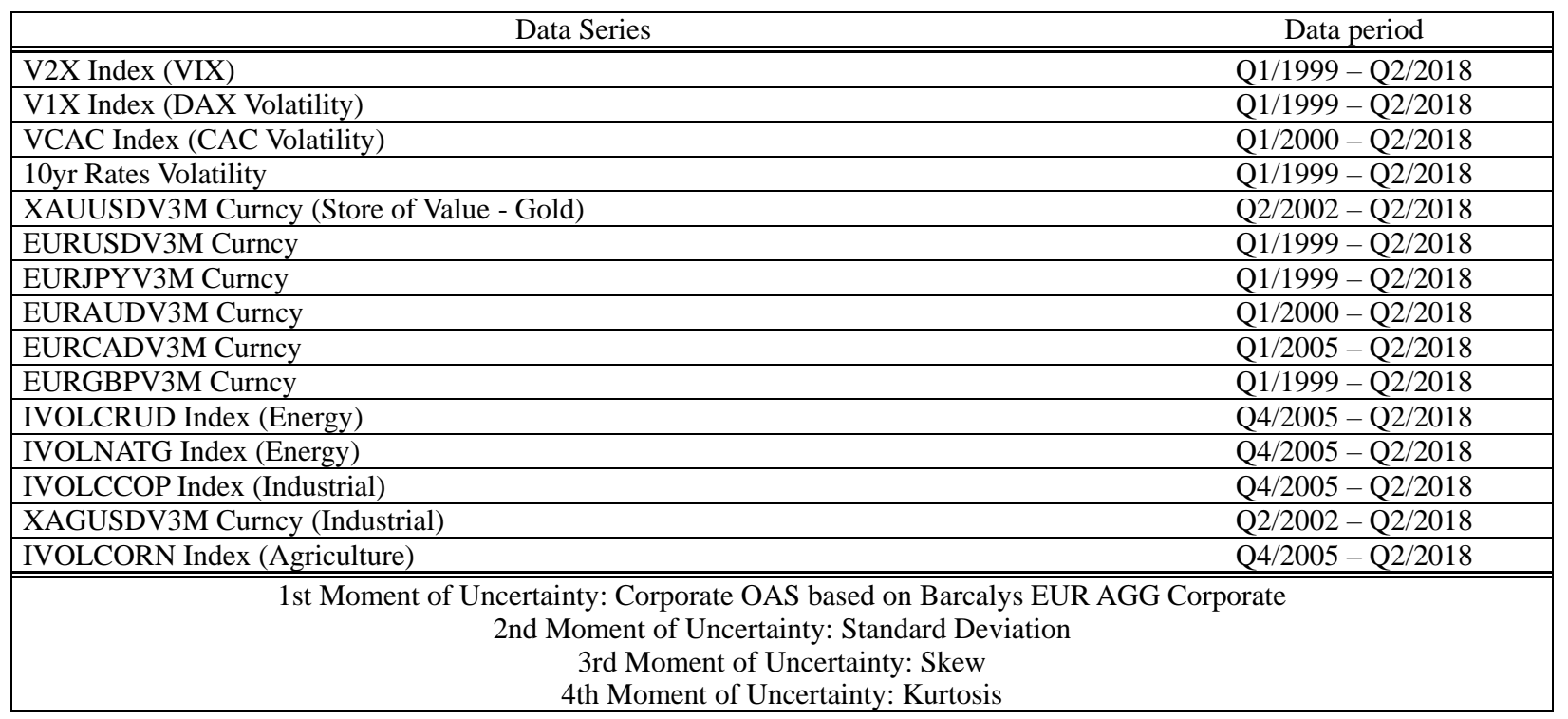

Source: Bloomberg

In a next step, we construct aggregate measures of uncertainty across the different economic agents. For the aggregate first moment and second moment, we use principal component analysis to combine the different point estimates ${ }^{13}$ (factor loadings: Consumer 32\%, Corporates 35\%, Financial Markets 33\%) and the standard deviation (factor loadings: Consumer 15\%, Corporates 39\%, Financial Markets 46\%). The study refers to principal component analysis to describe the systemic nature of uncertainty expressed through the factor loadings of the first principal vector that explains most of the variation in the data. Hence, the first moment emerges almost equally from the three different economic groups, while the dispersion around the point estimate applies a higher weight to the dispersion within the corporate sector and financial markets. For the aggregate measures of the skewness and kurtosis, the study uses equal weighting given a later starting date of the financial time series and the decision to not standardize skewness and kurtosis given the more useful interpretation of their original scaling.

This model set-up yields four aggregate indices representing the different moments of uncertainty. Each aggregate moment is made up of three sub-indices covering the different economic agents.

\subsection{Construction of the VAR and the Impulse Response Functions}

To estimate the impact of uncertainty on real GDP, we construct a VAR that includes two additional real economic variables reflecting broader business cycle dynamics and the four moments of uncertainty:

$$
\left[\begin{array}{c}
\mathrm{GDP}_{\mathrm{t}} \\
\mathrm{IP}_{\mathrm{t}} \\
\pi_{\mathrm{t}} \\
1^{\text {st } U} \\
2^{\text {nd }} \mathrm{U} \\
3^{\text {rd } U} \\
4^{\text {th }} \mathrm{U}
\end{array}\right]=A+\operatorname{Lag}\left[\begin{array}{c}
\mathrm{GDP}_{\mathrm{t}} \\
\mathrm{IP}_{\mathrm{t}} \\
\pi_{\mathrm{t}} \\
1^{\text {st } U} \\
2^{\text {nd }} \mathrm{U} \\
3^{\text {rd } U} \\
4^{\text {th }} \mathrm{U}
\end{array}\right]+\varepsilon_{t}
$$

The four moments of uncertainty, $1^{\text {st }} \mathrm{U}, 2^{\text {nd }} \mathrm{U}, 3^{\text {rd }} \mathrm{U}, 4^{\text {th }} \mathrm{U}$, represent the aggregate vectors across the three different economic groups. For all real economic variables, the study considers the quarterly difference of the natural logarithm. For GDP, we include a measure of real GDP. For IP, we consider the Industrial Production Index excluding construction. For $\pi$, the analysis refers to a measure of core inflation represented by the HICP excluding Energy \& Unprocessed Food. We further test for four lags of the VAR representation.

13 The option-adjusted-spread for corporate bonds is not available before Q3 2000, hence, we combine the corporate and the consumer via a simple average until that point. 
To infer the predictive value of each moment of uncertainty on real GDP via impulse response functions, we apply a one-standard deviation shock to the innovations of each uncertainty vector. We use the Cholesky decomposition of the covariance matrix and order the variables based on our hypothesis of the degree of endogeneity. ${ }^{14}$

\subsection{Out-of-Sample Assessment of Forecast Accuracy}

In order to assess whether the different moments of uncertainty contribute to the forecasting quality of the model, we estimate rolling out-of-sample GDP forecasts for the one quarter horizon. We proceed by estimating the VAR from Q1 1999 until Q1 2008 which is the last quarter before growth of real GDP hits negative territory. We start by forecasting GDP for the next quarter and calculate the root sum squared error term:

$$
\text { Root Sum Squared Error }=\sqrt{\frac{\sum_{i=1}^{N}(\text { Forecast of GDP-GDP })_{i}^{2}}{N-1}}
$$

We repeat the same exercise moving one quarter forward while keeping the starting date of the VAR fixed at Q1 1999 until we reach Q1 2018. The variable $\mathrm{n}$ represents the number of forecasts which is 41 for this set-up. We estimate this forecast error for 5 different models. The benchmark model represents a parsimonious definition containing only the three real economic variables. Models 2 to 5 include an increasing number of uncertainty vectors beginning with the first moment and adding stepwise the standard deviation, the skewness and the kurtosis.

\subsection{Validation of Results}

A common argument in literature is the dominant effect of the point estimate of confidence on the latter moments of uncertainty. If we observe that any of the latter moments (standard deviation, skewness and kurtosis) increases the model's forecasting accuracy, we will examine whether this effect is primarily driven by the first moment or by a genuine exogenous shock coming from the particular moment itself. Following a purging procedure described in Hatzius et al. (2010), we estimate a linear OLS regression model with the respective latter moment as the determinant variable and the first moment as the explanatory variable. We interpret the standardized error terms as the latter moment purged of the first moment and re-estimate the out-of-sample forecasting model.

\section{Results}

In a first step, we describe the nature of the different moments of uncertainty qualitatively vis-à-vis the business cycle. Secondly, we shock the different uncertainty variables by one standard deviation of their innovations and examine the effect on GDP. Third, we assess whether adding different moments of uncertainty increases the forecast accuracy of a VAR model via rolling out-of-sample forecasts and validate subsequently the results with regard to potential endogeneity.

\subsection{Behavior of the Different Moments}

All four moments are negatively correlated with GDP ranging from -0.77 to -0.05 . In line with our initial assumption, an increase of each moment is associated with a decrease in GDP growth for the first three moments and less conclusive results for the fourth moment (see Table 2 and Figures 1 and 2 for this).

Table 2. Correlation of Variables

\begin{tabular}{ccccccc}
\hline & Real GDP & IP & Core Inflation & 1st Moment & 2nd Moment & 3rd Moment \\
\hline Real GDP & 1,00 & 0,89 & $-0,07$ & $-0,77$ & $-0,59$ & $-0,38$ \\
IP & 0,89 & 1,00 & $-0,09$ & $-0,59$ & $-0,51$ & $-0,31$ \\
Core Inflation & $-0,07$ & $-0,09$ & 1,00 & $-0,05$ & 0,06 & 0,16 \\
1st Moment & $-0,77$ & $-0,59$ & $-0,05$ & 1,00 & 0,62 & 0,50 \\
2nd Moment & $-0,59$ & $-0,51$ & 0,06 & 0,62 & 1,00 & 0,10 \\
3rd Moment & $-0,38$ & $-0,31$ & 0,16 & 0,50 & 0,10 & 1,00 \\
4th Moment & $-0,05$ & 0,03 & 0,07 & $-0,02$ & $-0,14$ & 0,18 \\
\hline
\end{tabular}

\footnotetext{
${ }^{14}$ We assume that the real economic variables have a higher degree of endogeneity.
} 


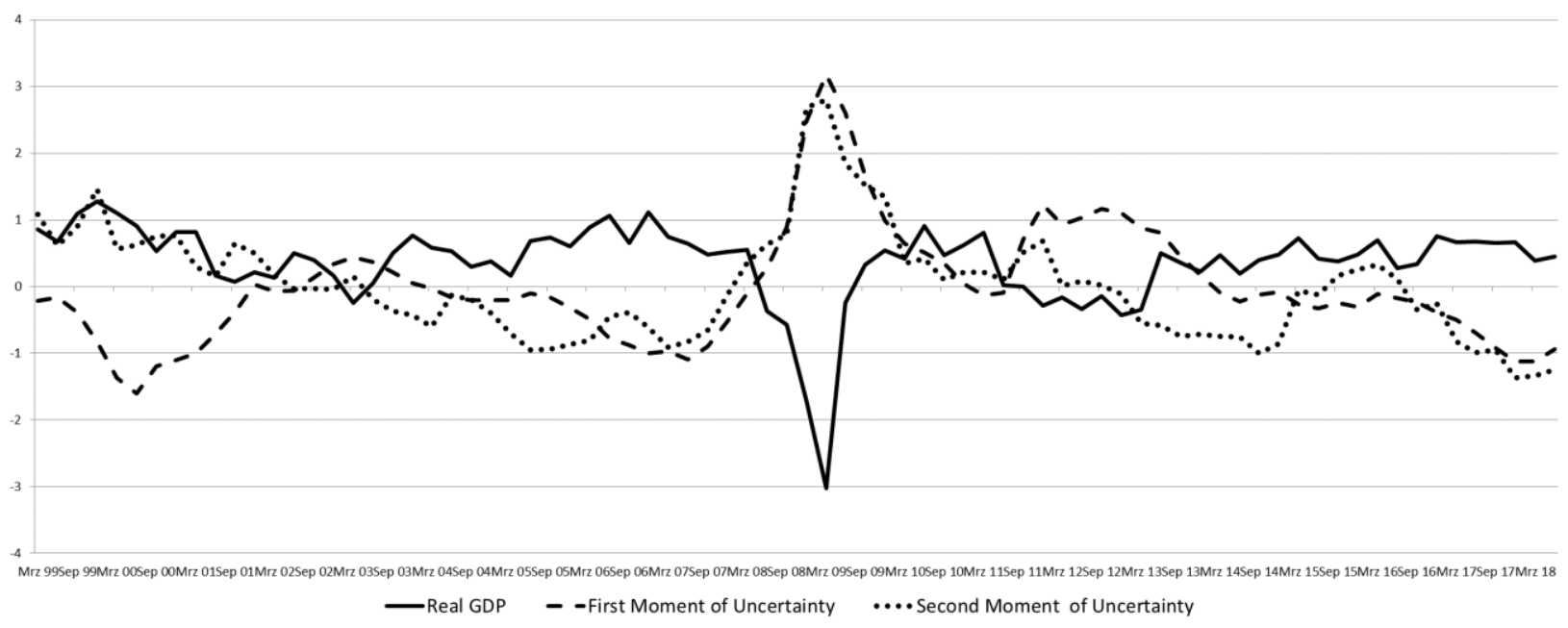

Figure 1. First and Second Moment of Uncertainty

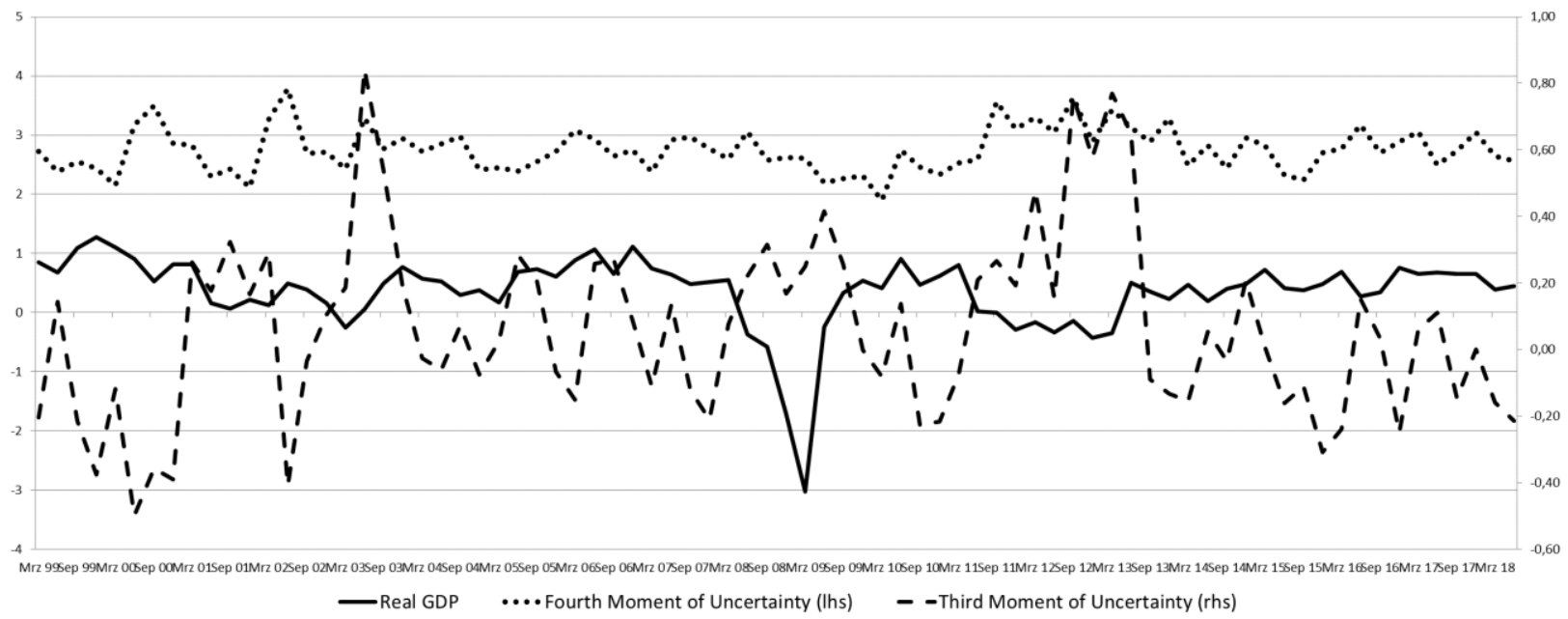

Figure 2. Third and Fourth Moment of Uncertainty

The first moment of uncertainty [Figure 3] peaks three times during the last 20 years and tracks closely the GDP dynamics with a correlation of -0.77 . Not only does the first moment reflect all three periods where economic growth turned negative (the economic contraction in Q1 2003, the Global financial crisis (GFC), the European peripheral debt crisis), but it also captures the magnitude of each of these economic periods very well. The index reaches its highest level during the GFC by increasing to 3.2 standard deviations above historical levels. From its through in Q2 2007, the index needs 7 quarters to hit its global peak in Q1 2009. This period coincides with the steepest quarterly decline of GDP during the GFC of $-3 \%$. During the European peripheral debt crisis, the amplitude of the index is more contained at 1 standard deviation above historical levels, representing the second largest peak. However, the first moment maintains an average level of 1 standard deviation for approx. 7 quarters which reflects strained confidence levels until the preliminary resolve through concerted action taken by the ECB and the European Commission. The third largest peak of the index occurs in Q1 2003, when growth of the euro area was lingering in negative territory for about a quarter. In line with the mild level of economic distress at that time, the uncertainty index enters positive territory but peaks already at 0.4 standard deviations. For the rest of the period, the index remains below zero without major fluctuations which underlines the benign economic periods between Q4 2003 to Q4 2007 and Q2 2013 to Q2 2018. The qualitative assessment of the first moment lends support to the hypothesis that the underlying input factors are largely representative of business cycle dynamics. 


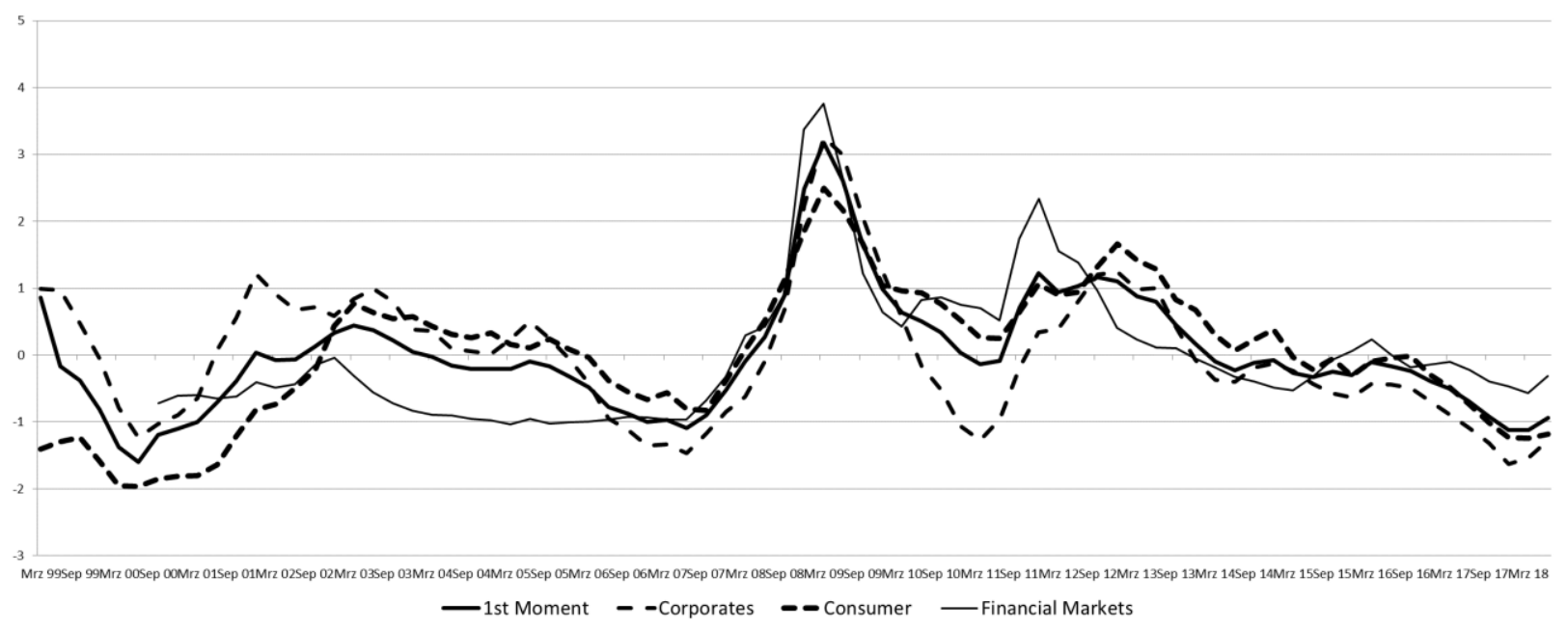

Figure 3. Decomposition of the First Moment of Uncertainty

The second moment of uncertainty [Figure 4] is also strongly negatively correlated with GDP growth at -0.59 . Given that the calculation of the first and the second moment was conducted based on the same dataset (with the exception of financial data), we interpret the second moment as the level of conviction that consumers, corporates and financial markets have about their first moment confidence estimate. Considering positive correlation of 0.62 between the first and the second moment, the observer is inclined to associate periods of high uncertainty with higher dispersion around the point estimate. On the same note, periods of lower uncertainty are associated with higher unanimity in the outlook. However, as we deconstruct this summary statistic into sub-periods, we learn that the overall positive correlation between the first and the second moment of uncertainty can be split into a pre-crisis period before the GFC exhibiting actually negative correlation and a period with very strong co-movement thereafter. For the period between Q1 1999 and Q4 2007, results indicate a correlation of -0.17 which highlights that the second moment did not behave pro-cyclically. During the first years after the formation of the euro area, the point estimate of uncertainty (first moment) shows generally high confidence among economic agents. The second moment, however, reveals a sustained higher dispersion around this estimate and disagreement within the corporate sector, among consumers and on financial markets lingering below the surface. In fact, the high level of dispersion around this estimate is only surpassed by the levels observed during the GFC.

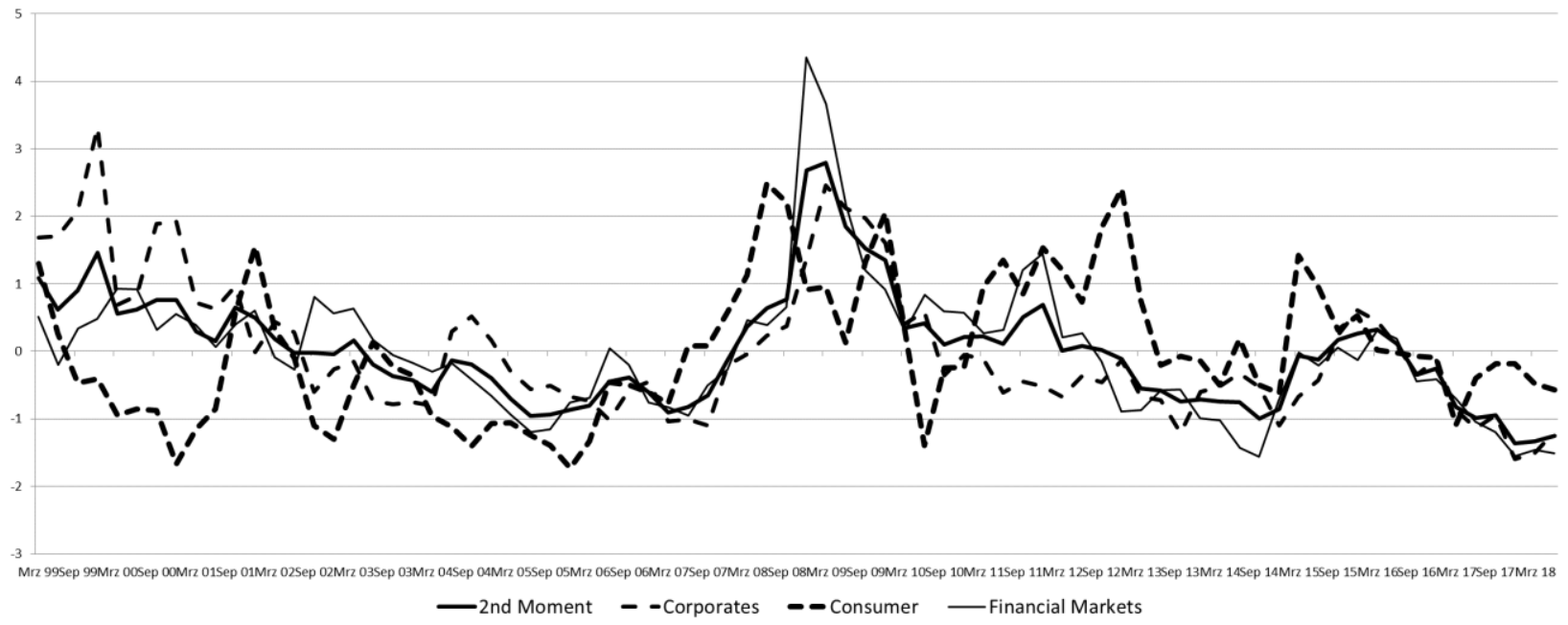

Figure 4. Decomposition of the Second Moment of Uncertainty

Looking at the period from Q1 2008 to Q2 2018, the correlation of both moments changes substantially and stands at 0.83 . The strong increase of uncertainty during the GFC coincides with less consensus among economic agents about 
their confidence estimate. We observe similar co-movement of both moments for the time period between Q2 2015 and Q2 2018 with a correlation of even 0.90. Despite potentially disruptive events (e.g. Brexit, U.S. election in 2016, the Greek debt crisis), both indices remain consistently low which underlines a high degree of unanimity among economic agents. In order to validate our initial belief of a structural break in the relationship between both time series, we conduct a test for structural change (Chow, 1960) that assumes that the first moment is explanatory for the second moment ${ }^{15}$. The model supports our initial assumption of a structural break in Q1 2008 (last quarter before negative GDP growth) and rejects the null hypothesis of coefficient stability at the $1 \%$ significance level.

The third moment [Figure 5] is negatively correlated with GDP at -0.38 and positively correlated with the first and second moment of uncertainty. Providing insights into the symmetry of the distribution, positive skewness is associated with negative growth. During periods of benign economic conditions, we tend to observe a moderately left skew with only a few outliers on the left-hand side of the distribution. As most markets participants gather on the positive spectrum, this creates ample room on the left-hand side of the confidence distribution for outliers who create the respective skew. When the crisis hits, people tend to revise their confidence level downward and collective herd behavior forces the median to fall below the mean of the distribution. At later stages of a crisis, the sustained positive skew is likely to be driven by positive outliers on the right-hand side who expect improving economic prospects ${ }^{16}$. Over the last two decades, we can observe positive skewness peaking three times. These local maxima coincide again with the three economic downturns that also come with the spike in the first moment. However, the nature and amplitude of these increases differ with the European peripheral debt crisis representing the most persistent positive skewness. During the period between Q1 2011 and Q1 2013, the positive skewness continuously rises while the first moment remains steadily at the same uncertainty level. A similar gradual increase of the positive skew is evident during the GFC, however, to a significantly lower amplitude.

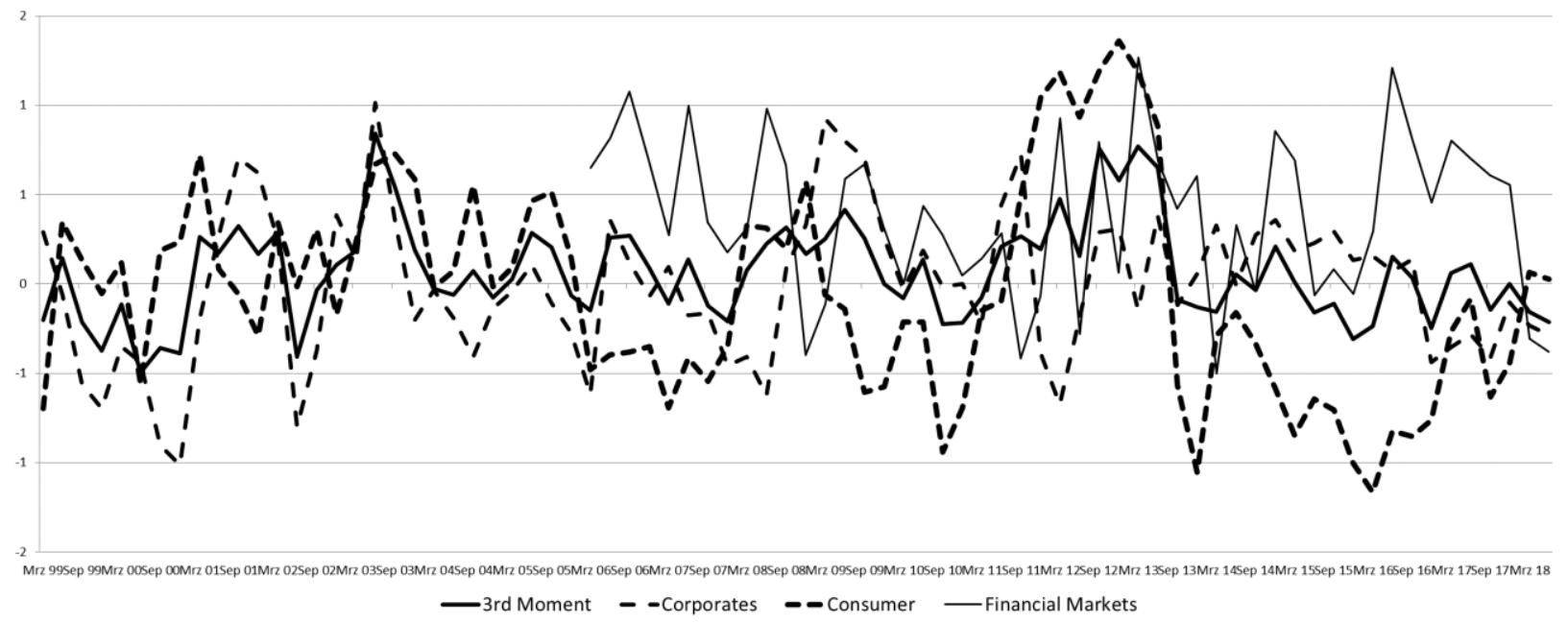

Figure 5. Decomposition of the Third Moment of Uncertainty

The fourth moment of uncertainty has a correlation of -0.05 with GDP growth and a correlation between -0.14 and 0.18 with the three other moments of uncertainty [Figure 6]. Hence, it appears to be almost uncorrelated with the business cycle. Over the last two decades, there is only the period between Q3 2011 and Q2 2013 in which the fourth moment attributes a persistent leptokurtic shape to uncertainty. This suggest that most of the economic agents have gathered around the points estimate with a few extreme outliers. The latter characteristic could be explained by the very binary nature of the redenomination risks that were surfacing during the European peripheral debt crisis. In contrast, the period leading up towards the GFC and the economic downturn itself did not coincide with a higher dispersion of confidence estimates in the tails.

\footnotetext{
${ }^{15}$ As literature often assumes that the first moment has an effect on the second moment of the distribution, we model the Chow test with the first moment as the explanatory variable.

${ }^{16}$ For the financial time series, periods of crisis show also a right skew with extreme outliers on the upper volatility spectrum.
} 


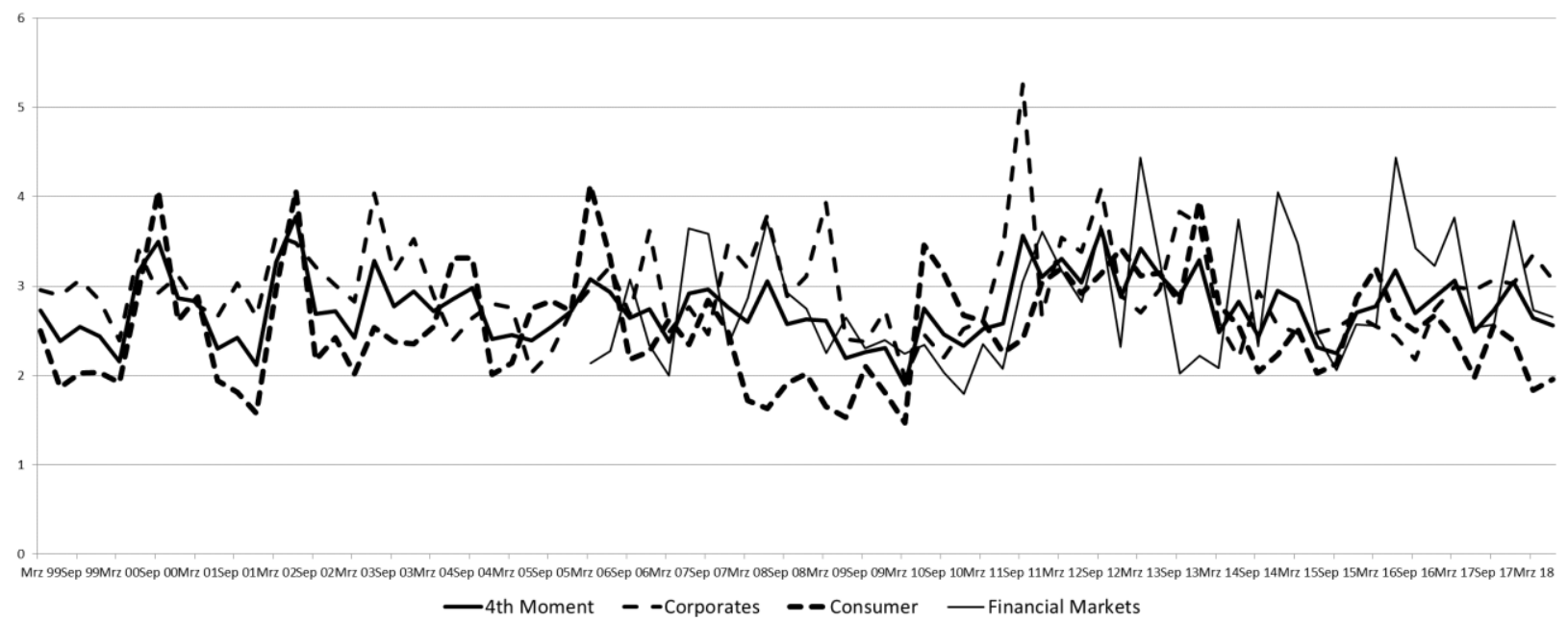

Figure 6. Decomposition of the Fourth Moment of Uncertainty

\subsection{The Effect of Uncertainty on GDP Growth}

The impulse response function is based on a VAR with a lag structure of 2 based on the AIC criterion. This result suggests that uncertainty and real economic variables impact one another with a lag of up to 6 months. To further examine the role of the various economic groups, we differentiate in a second step between consumers, corporates and financial markets.

A one-standard deviation shock to the first moment of uncertainty [Figure 7] leads to a cumulative decline in GDP of $-1.1 \%$ over the first two years. While the effect during the first year is $-0.9 \%$, the impulse on GDP leaves negative territory by the $8^{\text {th }}$ quarter and leads to some degree of growth overshooting in the annual range of $0.2 \%$ before it dies out after additional 3 years. As the overshooting makes up for around half of the growth detraction, the model suggests that an uncertainty shock has a persisting effect on the level of GDP but not on the growth rate. An innovation to the second moment leads to a cumulative decline of GDP by $-0.6 \%$ over the first two years with a subsequent moderate overshooting of growth. Results mirror the findings for the first moment, however, with a lower amplitude. Even though the impulse response function for a shock on the third moment of uncertainty shows overall similar dynamics in its impulse on GDP, the effect is significantly lower in absolute terms (-0.1\% of GDP in the first year). With regard to the kurtosis, the impulse response on GDP to a shock to the fourth moment is negligible ( $0.02 \%$ in the first year).

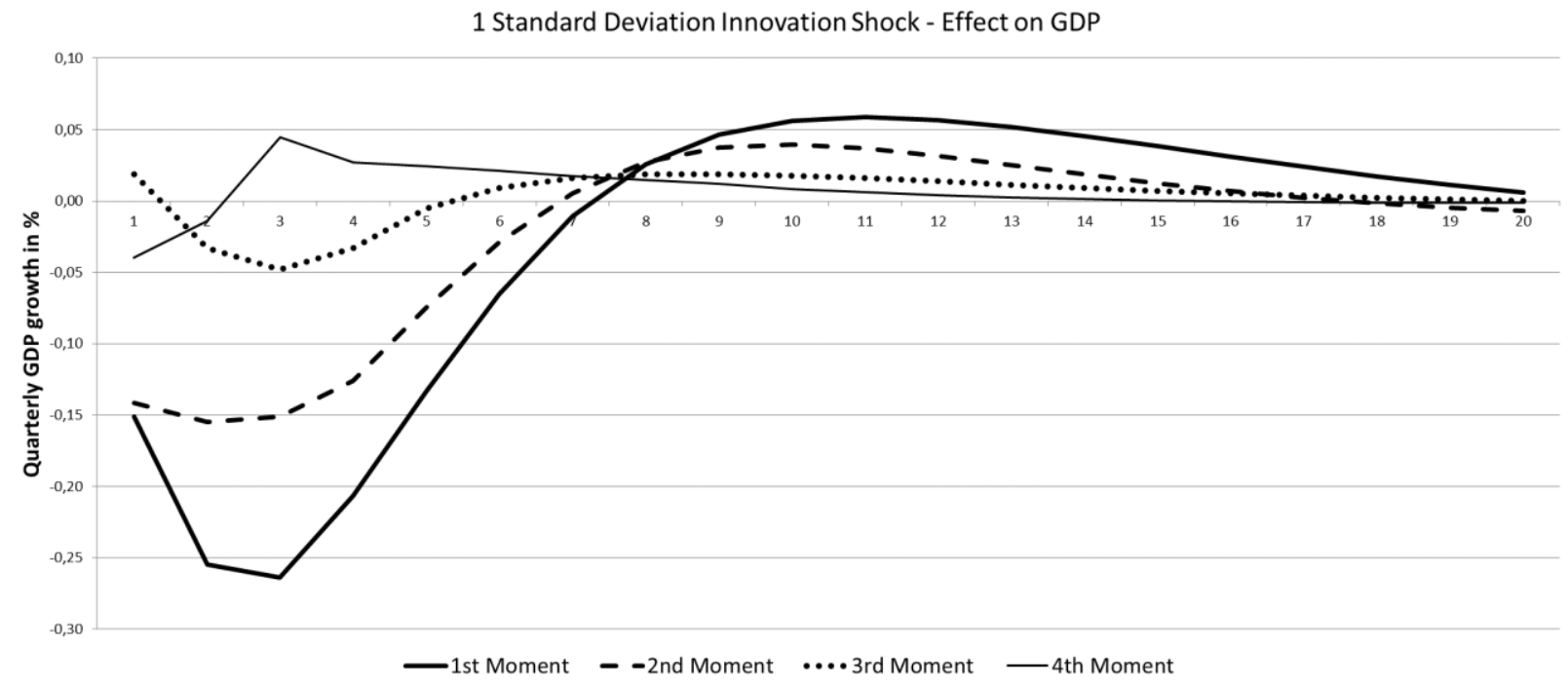

Figure 7. Impulse Response Function and Effect on GDP 
Decomposing the shock to the first moment of uncertainty into the vectors' three subcomponents through individual impulse response functions, we can attribute the largest impact to the corporate sector by $-1 \%$ GDP growth in the first year [Figure 8]. Interestingly, financial markets exert a similarly sized shock in the first quarter, however, the effect is much less persistent and returns to a positive impulse on growth already after the first year.

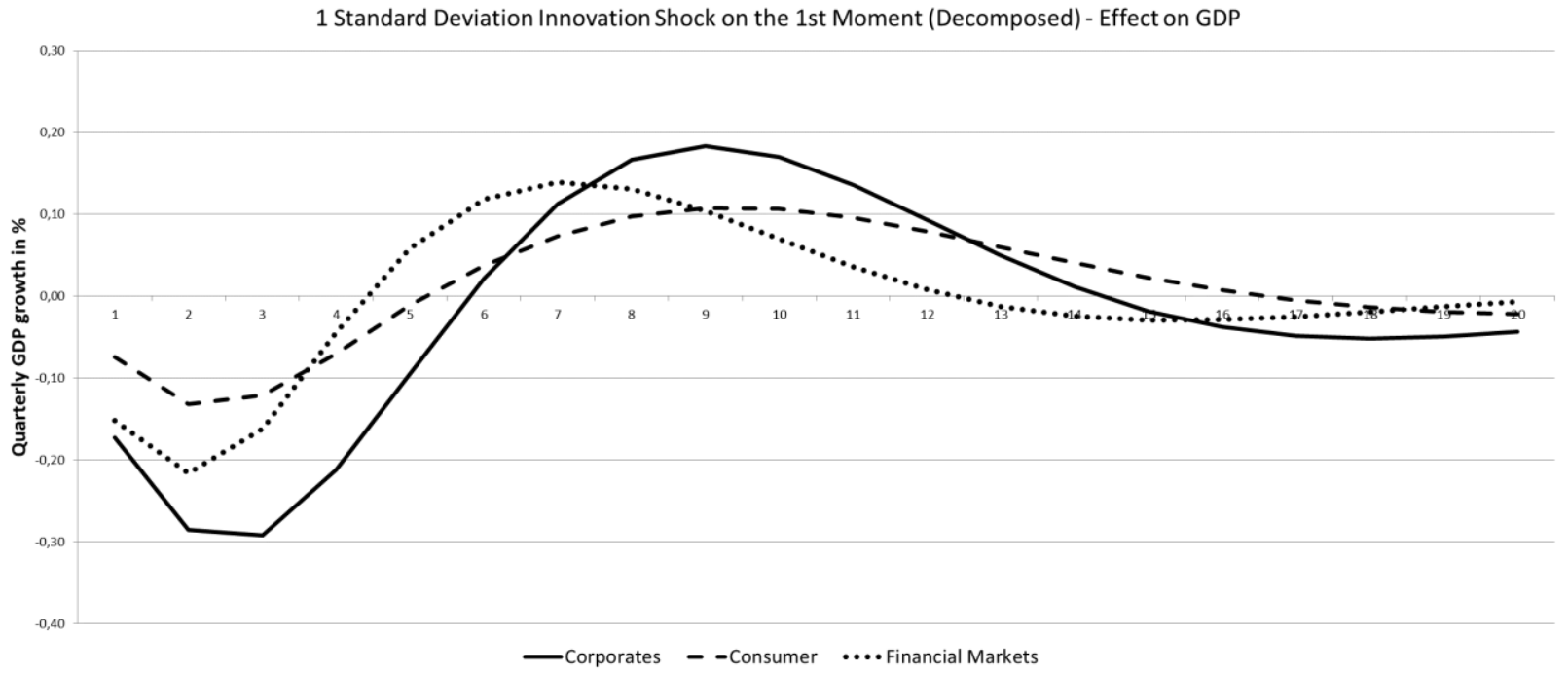

Figure 8. Decomposition of the Impulse Response Function (First Moment)

With regard to the decomposition of the second moment of uncertainty, results confirm that a financial markets shock is again less persistent in its effect on the real economy compared to an impulse stemming from the other two economic agents [Figure 9]. Despite the overall lower amplitude, the consistency across the different agents lends credibility to the idea that positive skewness carries significant informative value regarding a decline in GDP.

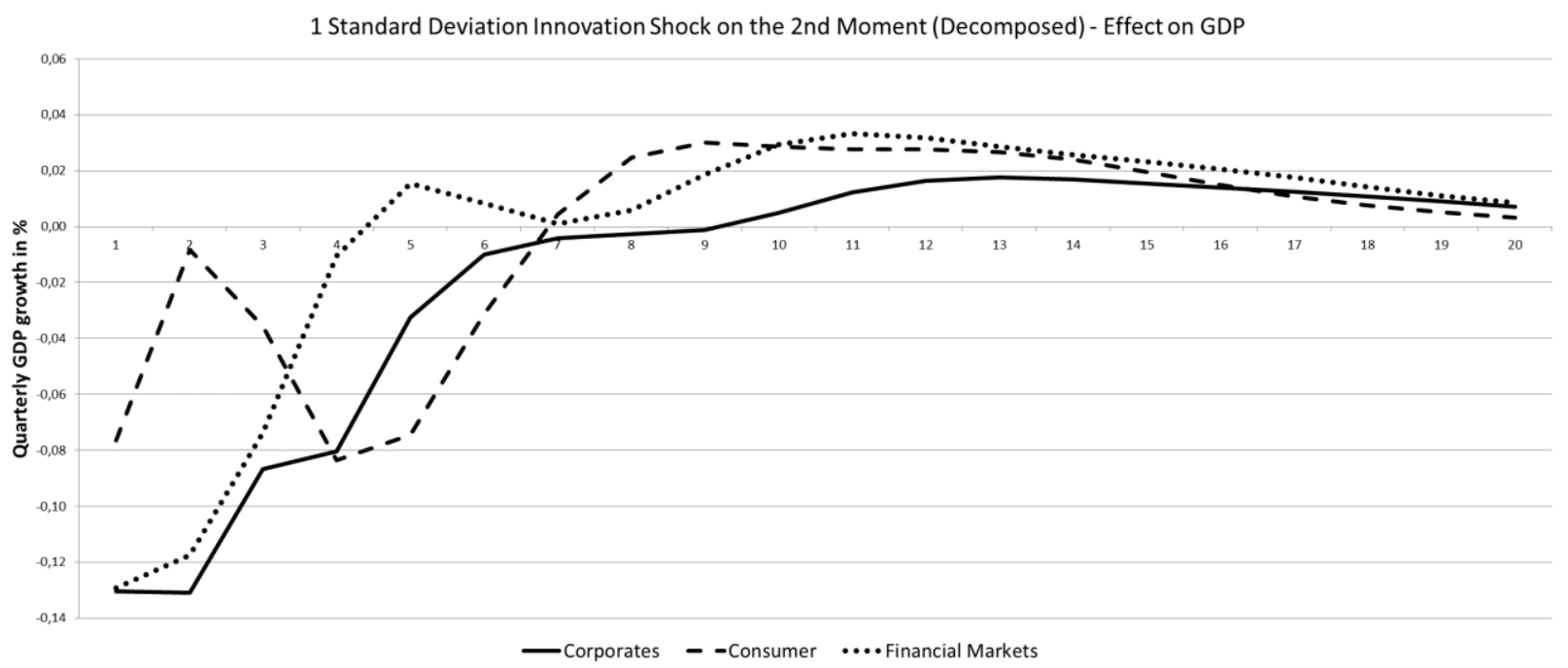

Figure 9. Decomposition of the Impulse Response Function (Second Moment)

\section{Predictive Value of Uncertainty in GDP Forecasts}

In this section, we examine how the addition of the four moments affects the VAR model's forecast accuracy on real GDP growth over the one-period horizon and subsequently test for the role of endogeneity.

\subsection{Results of the Different Forecasting Models}

We estimate four VAR models starting with the three real economic variables and the first moment of uncertainty. For 
each additional model, we add another moment of uncertainty until we reach the full specification as outlined in section 3.3. The initial calibration considers the period between Q1 1999 and Q1 2008, which represents the last quarter before growth turned into negative territory during the recession of 2008-2009. We re-estimate the model by adding one additional quarter until we reach Q1 2018 and assess the root sum squared error term. To evaluate the relative performance, the study considers first a parsimonious benchmark model based on the three real economic variables [Table 3].

Table 3. Results of the Forecasting Models

\begin{tabular}{|c|c|c|c|c|c|c|c|c|c|c|}
\hline \multirow[b]{2}{*}{ Model } & \multicolumn{7}{|c|}{ Model Components } & \multicolumn{3}{|c|}{ Root Sum Squared Error } \\
\hline & $\begin{array}{l}\text { Real } \\
\text { GDP }\end{array}$ & $\begin{array}{l}\text { Industrial } \\
\text { Production }\end{array}$ & $\begin{array}{c}\text { Core } \\
\text { Inflation }\end{array}$ & $\begin{array}{l}\text { 1st } \\
\text { Moment of } \\
\text { Uncertainty }\end{array}$ & $\begin{array}{l}\text { 2nd } \\
\text { Moment of } \\
\text { Uncertainty }\end{array}$ & $\begin{array}{l}\text { 3rd } \\
\text { Moment of } \\
\text { Uncertainty }\end{array}$ & $\begin{array}{c}\text { 4th } \\
\text { Moment of } \\
\text { Uncertainty }\end{array}$ & $\begin{array}{c}\text { Full } \\
\text { Period }\end{array}$ & $\begin{array}{l}\text { Recession } \\
\text { 2008-2009 }\end{array}$ & $\begin{array}{l}\text { Recession } \\
\text { 2011-2013 }\end{array}$ \\
\hline $\begin{array}{l}\text { Benchmark } \\
\text { Model }\end{array}$ & $\mathrm{X}$ & $X$ & $\mathrm{X}$ & & & & & 0,81 & 2,03 & 0,27 \\
\hline Model 1 & $\mathrm{X}$ & $X$ & $\mathrm{X}$ & $X$ & & & & 0,65 & 1,42 & 0,53 \\
\hline Model 2 & $\mathrm{X}$ & $\mathrm{X}$ & $\mathrm{X}$ & $\mathrm{X}$ & $\mathrm{X}$ & & & 0,63 & 1,38 & 0,60 \\
\hline Model 3 & $\mathrm{X}$ & $\mathrm{X}$ & $\mathrm{X}$ & $\mathrm{X}$ & $\mathrm{X}$ & $\mathrm{X}$ & & 0,68 & 1,50 & 0,58 \\
\hline Model 4 & $X$ & $\mathrm{X}$ & $\mathrm{X}$ & $X$ & $\mathrm{X}$ & $X$ & $X$ & 0,70 & 1,54 & 0,62 \\
\hline
\end{tabular}

The benchmark model produces a root sum squared error of 0.81 [Figure 10]. The reason for this relatively large forecast error can be traced back to the GFC between Q1 2008 and Q3 2009, which yields on an isolated basis a root sum squared error of 2.02. As the calibration period between Q1 1999 and Q1 2008 does not include a major downturn, the model's error term is rather large for the first economic contraction. For the second recession caused by the European peripheral debt crisis, the forecast accuracy of the model improves significantly yielding only a forecast error of 0.27 for this isolated period.

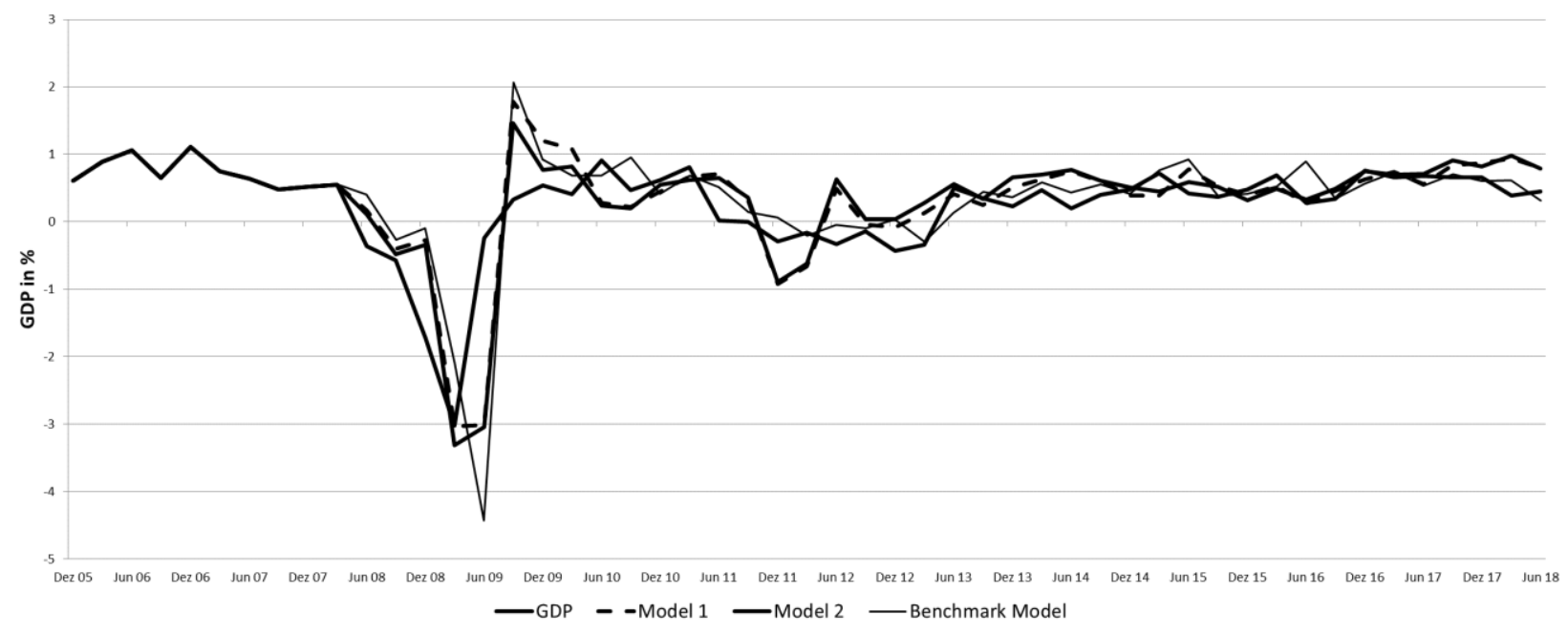

Figure 10. GDP Forecast - Benchmark Model, Model 1 and Model 2

The addition of the first moment of uncertainty (Model 1) improves the forecast accuracy over the total horizon substantially and generates a root sum squared error of 0.65 . This is due to a better performance during the first recession with error statistics of 1.42. The GDP forecast of Model 1 turns south to -3.03\% in Q1 2009 (actual growth $-3.02 \%$ ) versus a forecast of $-2.11 \%$ based on the benchmark model. Hence, the first moment of uncertainty seems to adequately capture the amplitude of the recession during the GFC. However, Model 1 fails to capture the quick rebound of growth back to $-0.24 \%$ in the subsequent quarter. Model 2, which incorporates both the first and second moment of uncertainty, improves the forecast accuracy further with an error term of 0.63 . The addition of the third moment and the 
fourth moment of uncertainty, however, decreases the model quality with an error term of 0.68 for Model 3 and 0.70 for Model 4 [Fig. 11].

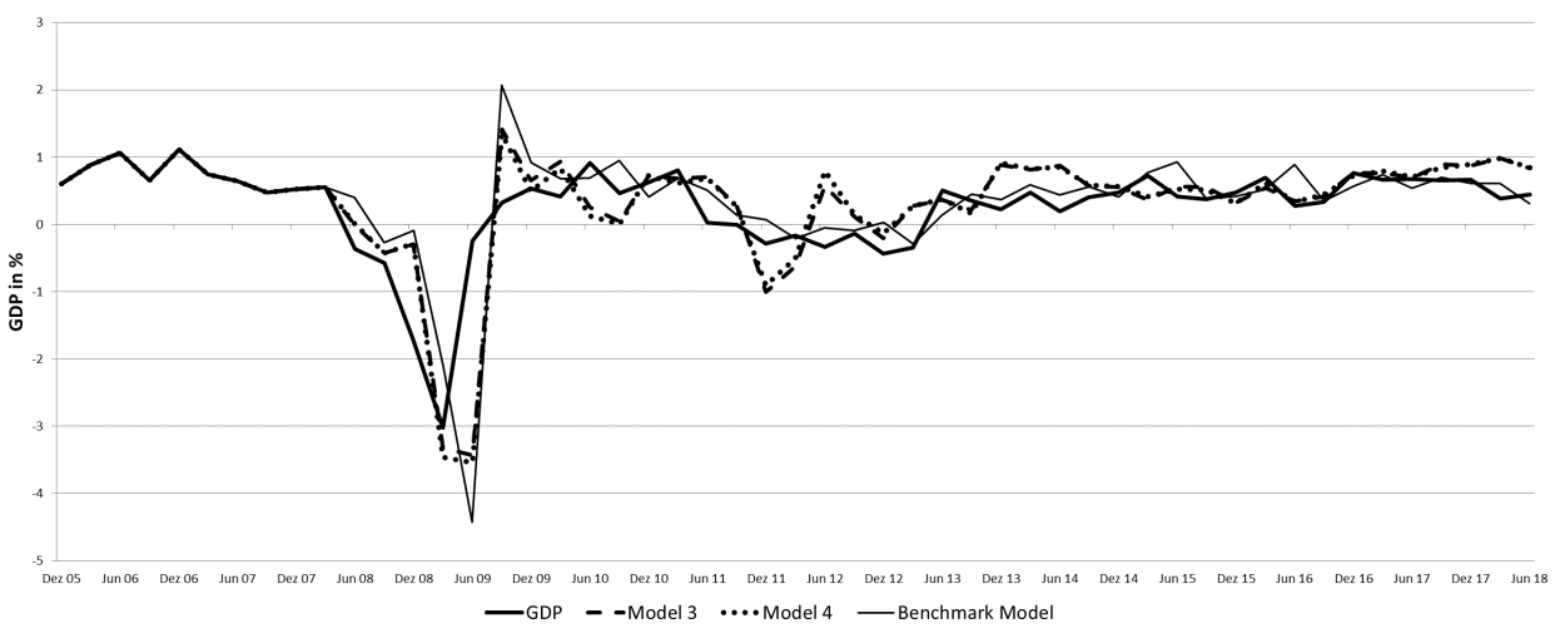

Figure 11. GDP Forecast - Benchmark Model, Model 3 and Model 4

We conclude that augmenting the benchmark model with the first moment of uncertainty clearly yields a significant improvement. On the addition of the second moment, we remain cautious and further investigate the relationship between the first and the second moment of uncertainty in the next section.

\subsection{Purging for the Exogenous Component of the Second Moment}

Results of the previous section provide some evidence that the second moment increases the forecasting ability of the VAR model on GDP growth. However, the question arises to what degree the dynamics of the second moment are actually driven by the first moment of uncertainty. To purge the second moment from the effect of the point estimate of confidence, we apply a regression method used by Hatzius et al. (2010). We estimate a linear OLS regression model with the second moment as the determinant variable and the first moment as the explanatory variable. Results suggest that $31 \%$ of the second moment can be explained by variation of the first moment. For the perspective of this analysis, we interpret the standardized error terms as the exogenous component of the second moment [Figure 12].

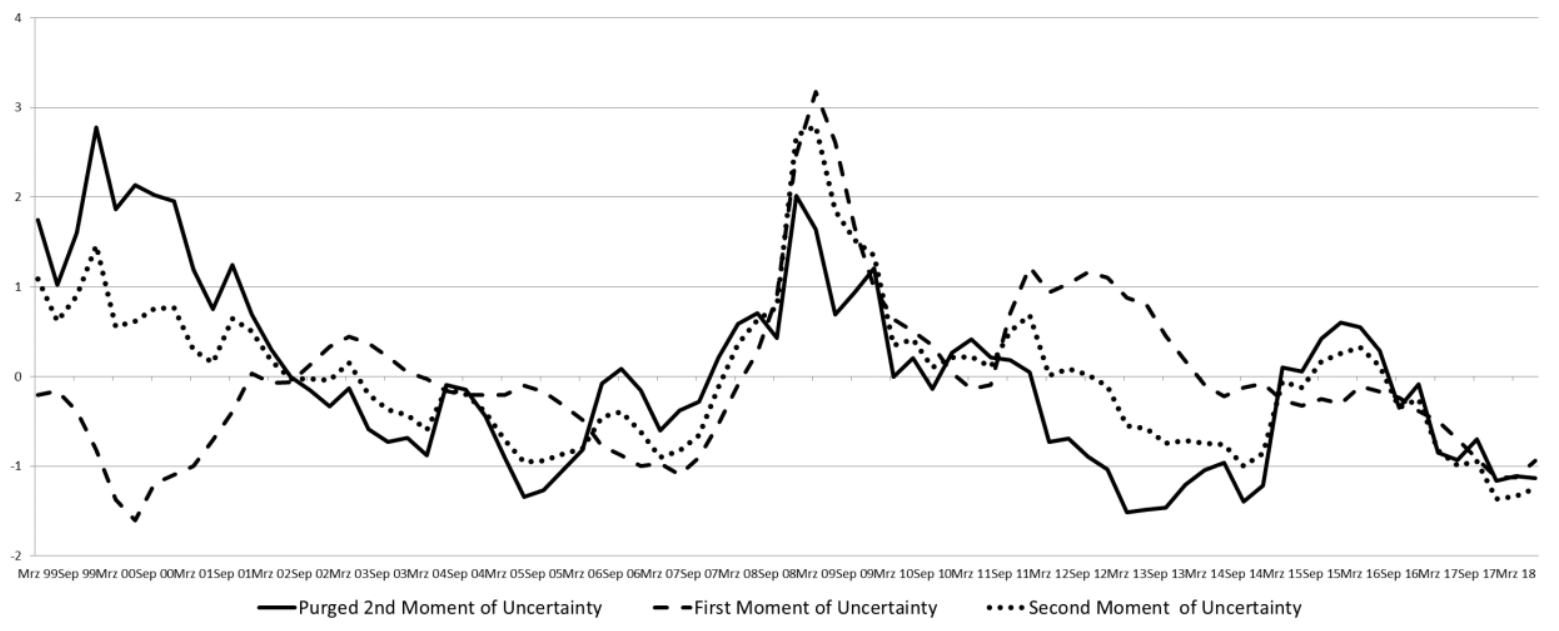

Figure 12. The Exogenous Component of the 2nd Moment of Uncertainty

The purged index reveals that the highest degree of dispersion occurs in the early days of the newly formed euro area. The levels are comparable to the heightened dispersion during the GFC. According to this revised index of the second moment, the dispersion of uncertainty during the European peripheral debt crisis was even below historical averages and rises again into positive territory during the flare-up of recession fears between Q3 2015 and Q2 2016. To quantify the predictive value of the purged index, we re-estimate Model 2 by replacing the second moment by the purged index of the second moment. The root sum squared error of the rolling GDP forecast remains at 0.63 which is consistent with the results of the unpurged version. Hence, we conclude that the second moment carries additional informative value 
that is not captured in the first moment of uncertainty.

\section{Conclusion}

We construct four different moments of aggregate uncertainty across consumers, corporates and financials markets. All four moments are negatively correlated with GDP growth with correlation coefficients ranging from -0.77 to -0.05 in increasing order. The qualitative assessment of the first moment lends support to the idea that point estimates of the confidence level are strongly representative of business cycle dynamics. The second moment of uncertainty is also strongly negatively correlated with GDP and displays how unanimous economic agents are about their point estimate. The analysis of the third moment reveals that positive skewness is associated with negative growth. While the initial increase of the skewness is probably driven by herd behavior, the continuous increase during a crisis could reflect optimistic outliers who act as harbingers for the recovery. The assessment of the fourth moment does not allow for firm conclusions about its relationship with the business cycle.

By quantifying the impact of uncertainty, impulse response functions suggest that a one-standard deviation shock to the innovations of the first moment of uncertainty leads to an initial cumulative decline in GDP of $-1.1 \%$ over the first two years which is reduced by half due to an overshoot of GDP growth over the subsequent years. This causes a permanent effect on the level of GDP, but only a temporary effect on the growth rate. By decomposing the shock on the first moment of uncertainty into its three sectors, we can attribute the largest impact to the corporate sector and observe the effect of financial markets being equally strong in the beginning but fading much quicker. A shock to the second and third moment of uncertainty causes similar dynamics like the first moment but with lower amplitude, whereas the kurtosis is negligible with regard to the impact on GDP growth.

We conclude that augmenting a parsimonious forecasting model on GDP by the first and second moment of uncertainty clearly improves overall forecast accuracy. As we remove the potential effect of the first moment on the second moment through a purging procedure, we can verify that the second moment carries informational value that is independent of the first moment improving the forecasting model further.

\section{References}

Abel, A. (1983). Optimal investment under uncertainty. The American Economic Review, 73, 228-233.

Adrian, T., \& Brunnermeier, M. K. (2016): "CoVar", The American Economic Review, 106, 1705-1741. http://dx.doi.org/10.1257/aer.20120555

Arellano, C., Bai, Y., \& Kehoe, P. (2011). Financial markets and fluctuations in uncertainty. Federal Reserve Bank of Minneapolis Research Department Staff Report.

Bachmann, R., Elstner, S., \& Sims, E. R. (2013). Uncertainty and economic activity: Evidence from business survey data. American Economic Journal: Macroeconomics, 5, 217-249. https://doi.org/10.1257/mac.5.2.217

Baker, S. R., Bloom, N., \& Davis, S. J. (2016). Measuring economic policy uncertainty. Quarterly Journal of Economics, 131, 1593-1636. https://doi.org/10.1093/qje/qjw024

Bekaert, G., Hoerova, M., \& Duca, M. L. (2013). Risk, uncertainty and monetary policy. European Central Bank Working Paper Series 1565, July 2013. https://doi.org/10.1016/j.jmoneco.2013.06.003

Bernanke, B. S. (1983). Irreversibility, uncertainty, and cyclical investment. Quarterly Journal of Economics, 97, 85-106. https://doi.org/10.2307/1885568

Bernhardt, D., Campello, M., \& Kutsoati, E. (2006). Who herds?. Journal of Financial Economics, 80, 657-675. https://doi.org/10.1016/j.jfineco.2005.07.006

Caballero, R. J. (1991). Earnings uncertainty and aggregate wealth accumulation. The American Economic Review, 81, 859-871.

Caggiano, G., Castelnuovo, E., \& Nodari, G. (2017). Uncertainty and monetary policy in good and bad times. Reserve Bank of Australia Research Discussion Paper 2017-06. https://doi.org/10.2139/ssrn.2939377

Chow, G. C. (1960). Tests of equality between sets of coefficients in two linear regressions. Econometrica, 28, 591-605. https://doi.org/10.2307/1910133

Christelis, D., Georgarakos, D., Jappeli, T., \& van Rooij, M. (2016). Consumption uncertainty and precautionary saving. DNB Working Paper No. 496, January 2016. https://doi.org/10.2139/ssrn.2698098

Deaton, A. S. (1991). Saving and liquidity constraints. Econometrica, 59, 1221-1248. https://doi.org/10.2307/2938366

Dynan, K. E. (1993). How prudent are consumers?. Journal of Political Economy, 101, 1104-1113. https://doi.org/10.1086/261916 
Ernst, E., \& Viegelahn, C. (2014). Hiring uncertainty: A new labour market indicator. https://doi.org/10.2139/ssrn.2411299

Ferreira, T. R. T. (2018). Stock market cross-sectional skewness and business cycle fluctuations. International Finance Discussion Papers 1223. https://doi.org/10.17016/IFDP.2018.1223

Gilchrist, S., \& Zakrajšek E. (2012). Credit spreads and business cycle fluctuations. The American Economic Review, 102, 1692-1720. https://doi.org/10.1257/aer.102.4.1692

Gilchrist, S., Sim, J., \& Zakrajsek, E. (2014). Uncertainty, financial frictions, and investment dynamics. NBER Working Paper No. 20038. https://doi.org/10.3386/w20038

Guvenen, F., Karahan, K., Ozkan, S., \& Song, J. (2015). What do data on millions of U.S. workers reveal about life-cycle earnings risk? Federal Reserve Bank of New York Staff Reports 710, February 2015. https://doi.org/10.3386/w20913

Haddow, H., Hare, C., Hooley, J., \& Shakir, T. (2013). Macroeconomic uncertainty: What is it, how can we measure it and why does it matter?. Bank of England Quarterly Bulletin, 53(2), 100-109.

Hahm, J., \& Steigerwald, D. G. (1999). Consumption adjustment under time-varying income uncertainty. Review of Economics and Statistics, 81, 32-40. https://doi.org/10.1162/003465399767923791

Hartman, R. (1972). The effects of price and cost uncertainty on investment. Journal of Economic Theory, 5, 258-266. https://doi.org/10.1016/0022-0531(72)90105-6

Hatzius, J., Hooper, P., Mishkin, F. S., Schoenholtz, K. L., \& Watson, M. W. (2010). Financial conditions indexes: A fresh look after the financial crisis. NBER Working Paper No. 16150. https://doi.org/10.3386/w16150

Jurado, K., Ludvigson, S. C., \& Ng, S. (2015). Measuring Uncertainty. The American Economic Review, 105, 1177-1216. https://doi.org/10.1257/aer.20131193

Knight, F. H. (1921). Risk, uncertainty, and profit. Boston, MA: Hart, Schaffner \& Marx; Houghton Mifflin Company.

Leduc, S., \& Liu, Z. (2016). Uncertainty shocks are aggregate demand shocks. Journal of Monetary Economics, 82, 20-35. https://doi.org/10.1016/j.jmoneco.2016.07.002

Madsen, J. B., \& McAleer, M. (2000). Direct tests of the permanent income hypothesis under uncertainty, inflationary expectations and liquidity constraints. Journal of Macroeconomics, 22, 229-252. https://doi.org/10.1016/S0164-0704(00)00130-0

McDonald, R., \& Siegel, D. (1986). The value of waiting to invest. Quarterly Journal of Economics, 101, 707-727. https://doi.org/10.2307/1884175

Oi, W. (1961). The desirability of price instability under perfect competition. Econometrica, 29, 58-64. https://doi.org/10.2307/1907687

Pindyck, R. S. (1991). Irreversibility, Uncertainty and Investment. Journal of Economic Literature, 29, 1110-1148. https://doi.org/10.3386/w3307

Romer, C. (1990). The great crash and the onset of the great depression. Quarterly Journal of Economics, 105, 597-624. https://doi.org/10.2307/2937892

Rossi, B., \& Sekhposyan, T. (2015). Macroeconomic uncertainty indices based on nowcast and forecast error distributions. The American Economic Review, 105, 650-655. https://doi.org/10.1257/aer.p20151124

Stokey, N. L. (2016). Wait-and-see: Investment options under policy uncertainty. Review of Economic Dynamics, 21, 246-265. https://doi.org/10.1016/j.red.2015.06.001

\section{Copyrights}

Copyright for this article is retained by the author(s), with first publication rights granted to the journal.

This is an open-access article distributed under the terms and conditions of the Creative Commons Attribution license which permits unrestricted use, distribution, and reproduction in any medium, provided the original work is properly cited. 